SESSION 5. EXPERTMENTAL ATOMIC PHYSICS 


\section{G.H. Dunn}

Joint Institute for Laboratory Astrophysics

University of Colorado, Boulder, CO 80309

The breakthrough in 1978 by Brooks et al. ${ }^{1}$ and by Breton et al. 1 provided the first plasma rate measurements on dielectronic recombination (DR), and their basic technique has been followed up on in a few other investigations. An 1mportant new plasma technique was introduced ${ }^{2}$ in 1982. Another breakthrough in 1982-1983 led to colliding beams cross section measurements ${ }^{3}$ for $D R$ and to more direct comparisons with theory. Experiment/theory disagreements and agreements have led to follow-up experimental and theoretical efforts which are pointing to better understanding of DR and which emphasize 1ssues that should be paid attention to by plasma modelers. An overview will be given with strong emphasis on the beams experiments and the implications.

* Staff Member, Quantum Physics Diivsion, National Bureau of Standards.

REFERENCES

R.L. Brooks et al. Phys. Rev. Lett. 41, 107 (1978); C. Breton et al. Phys. Rev. Lett. 41, 110 (1978).

3M. Bitter et al. Buil. Am. Phys. Soc. 27, 1083 (1982).

3 J.B.A. Mitchell et al. Phys. Rev. Let - 50, 335 (1983); B.S. Bellc et al. Phys. Rev. Lett. 50, 339 (1983); P.F. Dittner et al. Phys. Rev. Let $\bar{t}$. $1,31(1983) ;$ J.F. Williams, Phys. Rev. A 29,2936 (1984). 